\title{
COMMON FIXED POINTS FOR GENERALIZED CONTRACTIONS IN UNIFORM SPACES ENDOWED WITH A GRAPH
}

\author{
BOSHRA HOSSEINI and ALIREZA KAMEL MIRMOSTAFAEE*
}

\begin{abstract}
In this paper, we will define a new kind of generalized contractions to establish some common fixed point theorems for self-mappings on Hausdorff uniform spaces endowed with a graph. This new notion enables us to extend some known results in the literature. We also show that our results can be applied to a homotopy theorem. Related examples are also given to support our main results.
\end{abstract}

MSC 2010. Primary: 47H10; Secondary: 47H9,54E15, 05C40, 54H25.

Key words. Connectivity, fixed points, graph, uniform spaces.

\section{REFERENCES}

[1] M. Aamri and D. El Moutawakil, Common fixed point theorem for E-contractive or E-expansive maps in uniform spaces, Acta Math. Acad. Paedagog. Nyházi. (N.S.), 20 (2004), 83-91.

[2] A. Aghanians, K. Fallahi, K. Nourouzi and R.U. Verma, Fixed points for Ciric-Gcontraction in uniform spaces endowed with a graph, Publ. Inst. Math. (Beograd) (N.S.), 97 (2015), 211-233.

[3] A. Aghanians and K. Nourouzi, Fixed points for Kannan type contractions in uniform spaces endowed with a graph, Nonlinear Anal. Model. Control, 21 (2016), 103-113.

[4] S.M.A. Aleomraninejad, Sh. Rezapour and N. Shahzad, Some fixed point results on a metric space with a graph, Topology Appl., 159 (2012), 659-663.

[5] M.U. Ali, Fahimuddin, T. Kamran and E. Karapinar, Fixed point theorems in uniform space endowed with graph, Miskolc Math. Notes, 18 (2017), 57-69.

[6] N. Bourbaki, General topology, Addison-Wesley, 1966.

[7] P. Chaoha and S. Songsa-ard, Fixed points in uniform spaces, Fixed Point Theory Appl., 2014, Article 134, 1-13

[8] C. Chifu and G. Petrusel, Fixed points for multivalued contractions in b-metric spaces with applications to fractals, Taiwanese J. Math., 18 (2014), 1365-1375.

[9] J. Dugundji, Topology, Allyn and Bacon Series in Advanced Mathematics, Boston, 1966.

[10] E. Edelstein, An extension of Banach's contraction principle, Proc. Amer. Math. Soc., 12 (1961), 7-10.

[11] H. Faraji, K. Nourouzi and D. O'Regan, A fixed point theorem in uniform spaces generated by a family of b-pseudometrics, Fixed Point Theory, 20 (2019), 177-184.

The authors thank the referee for his helpful comments and suggestions.

*Corresponding author

DOI: $10.24193 /$ mathcluj.2020.1.06 
[12] J. Jachymski, The contraction principle for mappings on a metric space with a graph, Proc. Amer. Math. Soc., 136 (2008), 1359-1373.

[13] R.J. Knill, Fixed points of uniform contractions, J. Math. Anal. Appl., 12 (1965), 449455.

[14] A.K. Mirmostafaee, Coupled fixed points for mappings on a b-metric space with a graph, Mat. Vesnik, 69 (2017), 214-225.

[15] A.K. Mirmostafaee, Fixed point theorems for set-valued mappings in b-metric spaces, Fixed Point Theory, 18 (2017), 305-314.

[16] A. Nicolae, D. O'Regan and A. Petruşel, Fixed point hteorems for singlevalued and multivalued generalized contractions in metric spaces endowed with a graph, Georgian Math. J., 18 (2011), 307-327.

[17] A.C.M. Ran and M.C.B. Reurings, A fixed point theorem in partially ordered sets and some applications to matrix equation, Proc. Amer. Math. Soc., 132 (2004), 1435-1443.

[18] E. Tarafdar, An approach to fixed-point theorems on uniform spaces, Proc. Amer. Math. Soc., 191 (1974), 209-225.

Received October 18, 2018

Accepted March 14, 2019

Ferdowsi University of Mashhad
Department of Mathematics
Mashhad, Iran
-mail: bhosseini1395@gmail.com

E-mail: bhosseinil: mirmostafaei@ferdowsi.um.ac.ir 